\title{
M-learning Standardization: Concepts and New Ideas about Learner Profile
}

\author{
Fernando Mikic ${ }^{1}$ and Luis Anido ${ }^{1}$ \\ 1 ETSI Telecomunicación, University of Vigo \\ Lagoas Marcosende s/n, 36310 Vigo, Pontevedra, Spain \\ \{mikic,lanido\}@det.uvigo.es
}

\begin{abstract}
The Learning Technology (LT) standardization process is a hot topic today within the e-learning scientific community. This paper introduces the main LT specifications, and, specifically, presents several concepts about Learner Information standards, discussing some complements to them related to mobile learning.
\end{abstract}

\section{Introduction}

Standards can be defined as "documented agreements containing technical specifications or other precise criteria to be used consistently as rules, guidelines, or definitions of characteristics, to ensure that materials, products, processes and services are fit for their purpose" (ISO, 2002).

Concerning E-learning $\mathbf{n}$ particular, the process of standardization for the purposes of ensuring interoperability, portability and reusability, includes architectures and reference models, educational metadata, course structures, student assessment, content packaging and encapsulation, student management, runtime environments, and other specifications [1].

E-learning is a concept which comprises almost anything related to learning in combination with information and communication technology (ICT) [2]. We can define it as follows: "E-learning is the acquisition and use of knowledge distributed and facilitated primarily by electronic means."

In particular, E-learning is the use of internet technology for the creation, management, making available, security, selection and use of educational content to store information about those who learn and to monitor those who learn, and to make communication and cooperation possible.

M-learning, or Mobile E-learning, is fundamentally E-learning delivered through mobile computational devices (Palms, Windows CE machines, digital cell phones, 
MP3 players, etc.) [3]. So, mobile learning can provide online learners with capabilities to get instant notification by e-mail, access learning sites, report data from the field, and collaborate with learning colleagues.

But M-learning is much more than simply E-learning through mobile devices. As mobile devices evolve and people discover new ways in which the functionality of these devices can be applied to learning, mobile E-learning will become increasingly different from conventional E-learning and will create a new learning environment; an environment where learners have access to contents, teachers and other learners anywhere and anytime, where the contents they are accessing are dynamic and dependent on their location in space and time, and finally where learners can record any learning content for later use.

\section{LT standardization}

As we remark above, learning technology standardization is essential for use in systems design and implementation for the purposes of ensuring interoperability, portability and reusability; and there are many institutions and organizations involved in the standardization of E-learning technologies. The more significant domains of work of these bodies are:

- Metadata. Metadata is information about data or other information. Metadata describes how, when and by whom a particular set of data was collected, and how the data is formatted. Metadata standards have been developed to facilitate the management, discovery and retrieval of resources on the World Wide Web [4].

- Educational Modelling Languages. An Educational Modelling Language (EML) is a semantic notation to create units of learning to support the reuse of pedagogical entities such as learning designs, learning objectives, learning activities, etc. An EML describes not just the content of a unit of study (texts, tasks, tests, assignments) but also the roles, relations, interactions and activities of students and teachers [5].

- Learner Information. Learner Information specifications are dedicated to support the exchange of learner information between different systems. They provide data models, including the syntax and the semantics, to describe both the characteristics of a learner and his or her knowledge/abilities.

- Runtime. The basic tasks of runtime environments are content delivery to the student, support of the interaction between the content and the Learning Management System, and deciding the content to be delivered next depending on the static and dynamic course structure and previous student actions [6].

- Accessibility. Accessible design grants a wider range of learners more options and greater flexibility in learning. Presenting educational material in a variety of formats will also provide benefits to those with disabilities and/or with differing learning styles (visual, auditory, tactile) and will allow people to learn in their preferred learning style [7].

- Digital Repositories. Digital repositories store a collection of resources that can be retrieved through the network without knowledge of the collection structure.

- Content Aggregation. The need for educational resource sharing among learning systems and authoring tools motivated the development of common formats 
and procedures for encapsulating learning resources [8]. These encapsulated learning resources form a package including information about structural hierarchy and behaviors of its resources.

- Architectures and Interfaces. The purpose of developing system architectures is to discover high-level frameworks for understanding certain kinds of systems, their subsystems, and their interactions with related systems [9].

\section{Learner information}

Learner Information is a collection of information about a learner. The objective of these specifications is to allow the import data into and extraction of data from different systems. They provide data models, including the syntax and the semantics, to describe both the characteristics of a learner and his or her knowledge/abilities [10].

The information is associated with learners and used by Learner Information servers that may exchange data with Learner Delivery systems or with other servers. It is the responsibility of the Learner Information server to allow the owner of the learner information to define the information to be stored and shared.

Basically, information about a learner comes from three different sources: personal information, preferences, and academic information. In the following section we present various contributions to complete some standards and specifications about learner information, especially those related to learner's preferences, because it is in these preferences where specific characteristics of learning through mobile devices are reflected.

\subsection{Learner profile and device profile}

Inside the Learner Profile, a new type of structure, called Device Profile, will be created. The Device Profile addresses the characteristics of the device used by the learner for learning tasks. More specifically, the Device Profile stores a set of preferences about managing the device related to its particular characteristics. These preferences will be processed as "default preferences", which, if it is possible, will be finally used. To consider those cases in which these preferences can't be satisfied, some ranges of variation about them are defined. Obviously, these ranges must be supported by the considered device.

Ultimately, for facilitating the task of fully supporting the experience of learning according to conditions solicited from the learner, a set of values will be included that indicate the maximum capabilities supported by the device related to its characteristics (e.g., related to speed and types of connection, display capacity, etc.), and always carrying out the user's preferences. Furthermore, a learner can be in possession of several devices for use in learning; because of this, the learner must be able to complete his/her learning through all of them. Depending on his/her situation at the moment, he/she can select, from among all his/her devices, the one that is more convenient at that moment to achieve the learning tasks that he/she wants to complete. In such a case there will be not one Device Profile, but as many Device Profiles as the learner has "learning devices" to be used at his/her convenience. 
Therefore, three possible forms to implement the above exist:

- To include all the Device Profiles inside the same Learner Profile, which implies the system must be able to interact with each of the different Device Profiles within a single Learner Profile.

- To permit only one Device Profile per Learner Profile, which implies the existence of several Learner Profiles (at least one per Device Profile) with which the system must be able to interact.

- To permit both previous schemas, i.e., to permit several Learner Profiles (or only one), which can include one or more Device Profiles.

All of this implies the need for researching a set of services to manage all gathered information related to mobile devices. These services must be complete with a series of behavioural models that define how the data will be managed.

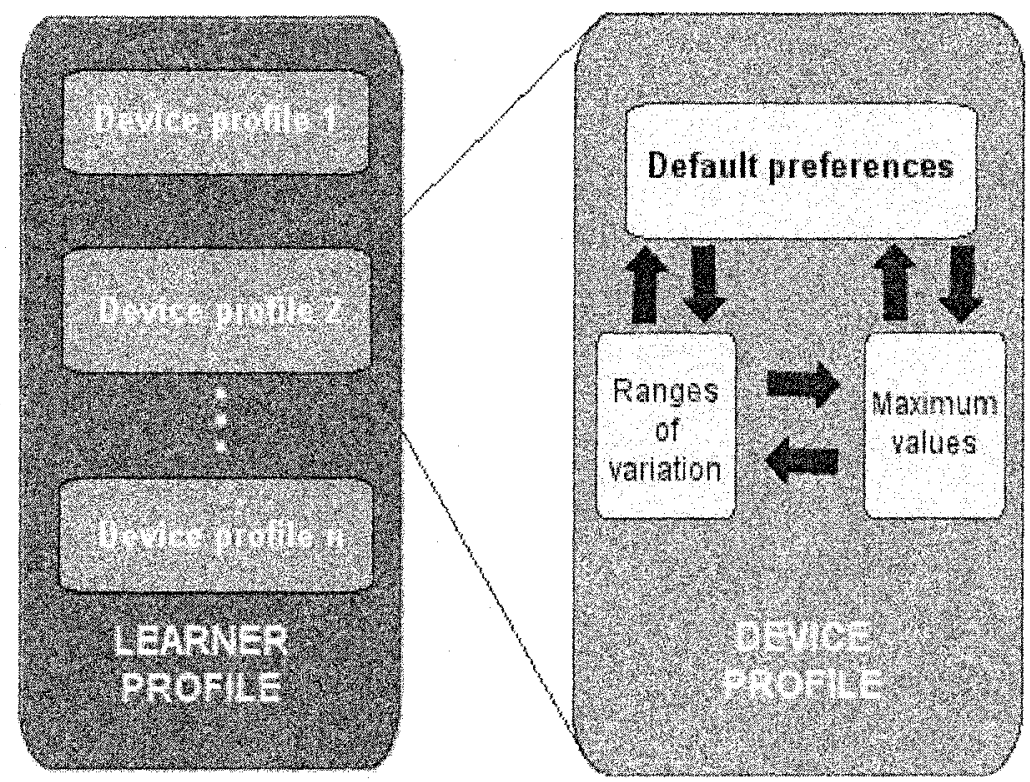

Figure 1. Learner Profile: A possible type of implementation.

The fact of having perfectly defined the different characteristics and capacities of each device that a learner can use for learning facilitates forming groups of learners who have devices with the same or compatible characteristics. To have a number of students with compatible devices in a group makes possible an easier and more effective process for them to interact with each other, and provides a better exploitation of resources as well. Furthermore, the fact that the students know about the existence of other students who use similar devices within their same group stimulates more feedback and sharing among them. Of course, feedback and sharing among learners having different devices must be possible and facilitated too. 


\section{Conclusions}

Throughout this paper we have presented several concepts such as "standardization", "E-learning" and "M-learning", and we have introduced the main LT specifications. Finally, we have addressed Learner Profile characteristics and we have proposed a set of upgrades for current Learner Profile standards that consider the special requirements and needs of $\mathrm{M}$-learning and its associated mobile devices.

\section{Acknowledgements}

We want to thank "Ministerio de Educación y Ciencia" for its partial support to this work under grant "MetaLearn: methodologies, architectures and languages for $\mathrm{E}$ learning adaptive services:" (TIN2004-08367-C02-01).

\section{References}

1. L. Anido, and M. Llamas, "A contribution to the e-learning standardization", Standardization and Innovation in Information Technology, 2001 2nd IEEE Conference, Boulder, CO, USA, 2001, 295-309.

2. S. Alexander, E-learning developments and experiences, Education + Training, Volume 43, Numbers 4-5, Emerald Group Publishing Limited, July 2001, pp. 240-248(9).

3. K. Nyíri, "Towards a Philosophy of M-Learning", Proceedings of the IEEE International Workshop on Wireless and Mobile Technologies in Education (WMTE'02).

4. M. Baca, Introduction to metadata: pathways to digital information, Los Angeles, Calif.: Getty Information Institute, 1998.

5. J. Rumbaugh, I. Jacobson, and G. Booch, The Unified Modeling Language reference manual, Essex, UK: Addison-Wesley Longman Ltd., 1998.

6. ADL Technical Team, Sharable Content Object Reference Model (SCORM), Advanced Distributed Learning (ADL), 2004.

7. M. Norton, and J. Treviranus, IMS Learner Information Package Accessibility for LIP Best Practice and Implementation Guide, IMS Global Learning Consortium, Inc., 2003.

8. O. Conlan, D. Dagger, and V. Wade, "Towards a Standards-based Approach to eLearning Personalization using Reusable Learning Objects", E-Learn 2002, World Conference on E-Learning in Corporate, Government, Healthcare and Higher Education, Montreal, September 2002.

9. IEEE P1484.1/D9, Draft Standard for Learning Technology - Learning Technology Systems Architecture (LTSA), Institute of Electrical and Electronics Engineers, Inc., 2001.

10. C. Smythe, F. Tansey, and R. Robson, IMS Learner Information Package Best Practice \& Implementation Guide, IMS Global Learning Consortium, Inc., 2001. 